\title{
UMA BREVE ANÁLISE DOS DOIS PRINCÍPIOS DA TEORIA DA JUSTIÇA DE JOHN RAWLS E SUAS IMPLICAÇÕES PARA A QUESTÃO ECONÔMICA
}

\author{
Antonio Ricardo Surita dos Santos*1
}

\section{Resumo}

A Teoria da Justiça de John Rawls apresenta princípios de liberdade e de igualdade equitativa de oportunidade destinados à construção de uma sociedade substancialmente justa. Para Rawls, sendo um empreendimento cooperativo para o benefício de todos, a estrutura social básica deve garantir vantagens a todos, especialmente aos mais necessitados. Em harmonia com a concepção de que as desigualdades sociais e econômicas somente podem ser aceitas diante da existência de vantagens efetivas dos menos afortunados, a teoria rawlsiana evidencia que os sistemas econômicos não podem estar desvinculados dos princípios de justiça e das questões morais.

Palavras-chave: Teoria da Justiça. Justiça como equidade. John Rawls. Liberdade. Eficiência econômica.

\section{A BRIEF REVIEW OF THE TWO PRINCIPLES OF JOHN RAWLS THEORY OF JUSTICE AND THEIR IMPLICATIONS FOR THE ECONOMIC ISSUE}

\begin{abstract}
The John Rawls' Theory of Justice presents principles of freedom and fair equality of opportunity to the construction of a substantially fair society. For Rawls, being a cooperative enterprise for the benefit of all, the basic social structure must guarantee advantages for all, especially those most in need. In harmony with the view that social and economic inequalities can only be accepted in the face of the existence of effective advantages for the less fortunate, rawlsian theory shows that economic systems cannot be disconnected from the principles of justice and moral issues.
\end{abstract}

Keywords: Theory of Justice. Justice as fairness. John Rawls. Freedom. Economic efficiency.

\section{INTRODUÇÃO}

Escrita na década de 1960 e lançada em 1971, a obra 'Uma Teoria da Justiça' de John Rawls foi um grande marco no campo da filosofia política, após praticamente um século de ausência de uma grande teoria nesse campo.

A Teoria da Justiça de Jonh Rawls, também denominada como justiça como equidade, é uma teoria substantiva que adota a justiça procedimental pura com o escopo de preservar o pluralismo moral de grande parte das sociedades contemporâneas, possibilitando, assim, que

\footnotetext{
* ${ }^{1}$ Doutorando em Filosofia do Direito pela Pontifícia Universidade Católica de São Paulo (PUCSP), Mestre em Direitos Fundamentais pela Universidade Metodista de Piracicaba (UNIMEP), Especialista em Direito Civil e em Direito Processual Civil pela Universidade Metodista de Piracicaba (UNIMEP) e Procurador do Município de São Paulo. (ricardo.surita@yahoo.com.br).
} 
cada indivíduo possa, com liberdade, escolher e seguir seus próprios objetivos de vida, inclusive com a garantia de igualdade equitativa de oportunidades.

Ao expressar que na "justiça como equidade, a sociedade é interpretada como um empreendimento cooperativo para o benefício de todos", Rawls (2008, pp. 5, 73, 75) formulou os dois princípios de justiça que sustentam sua teoria para a estruturação de uma sociedade justa, o primeiro garantindo que cada pessoa tenha "um direito igual ao sistema mais extenso de iguais liberdades fundamentais que seja compatível com um sistema similar de liberdades para as outras pessoas" e o segundo determinando que "as desigualdades sociais e econômicas devem estar dispostas de tal modo que tanto se possa esperar que se estabeleçam em benefício de todos como estejam vinculadas a cargos e posições acessíveis a todos".

Rawls deixa claro que a estrutura social não deve garantir melhores perspectivas para quem já está em melhor situação, salvo se isso for vantajoso para os menos afortunados e que os dois princípios estabelecidos são aplicados em "ordem serial ou léxica", ou seja, o primeiro princípio, o da liberdade igual, deve ser aplicado prioritariamente sobre o segundo, que estabelece critério para a existência de desigualdades sociais e econômicas. Desta forma, o primeiro princípio não pode ser limitado pelo segundo princípio, visto que as liberdades fundamentais somente podem ser restringidas quando houver conflito com outras liberdades fundamentais, não sendo possível sua redução em razão de questões relacionadas com a distribuição de renda e riqueza, por exemplo.

Assim, de um lado a teoria rawlsiana procura maximizar a extensão das liberdades garantidas aos indivíduos, como a liberdade de consciência, a liberdade de pensamento e a liberdade política, e de outro busca, através da interpretação democrática, restringir as arbitrariedades sociais e naturais e incentivar mecanismos que melhorem a situação dos menos afortunados.

A justiça como equidade é plenamente compatível com as exigências razoáveis de eficiência econômica, mas os sistemas econômicos não podem estar desvinculados dos princípios de justiça e das questões morais. Neste aspecto, Rawls adotará, com certas adequações, a "otimalidade de Pareto" como princípio de eficiência, estimulando a melhora de uma ou mais pessoas sem que haja piora na situação de outra(s) pessoa(s), e o critério econômico "maximin" para a escolha dos próprios princípios de justiça, procurando 
identificar, dentre as possibilidades disponíveis, ainda que numa situação de desconhecimento de informações particulares, a alternativa que não seja pior que as demais.

Sendo enfático ao declarar que "o princípio da eficiência não pode servir sozinho como concepção de justiça”, Rawls apresenta princípios de justiça essenciais na construção de uma sociedade contemporânea efetivamente justa.

O presente artigo adotou os métodos dialético e argumentativo, seguindo uma linha jurídico-exploratória.

\section{OS PRINCÍPIOS DA JUSTIÇA}

A obra 'Uma Teoria da Justiça' de John Rawls foi escrita na década de 1960, após praticamente um século de ausência de uma grande teoria no campo da filosofia política (VITA, 2008a, p. XII) e lançada em 1971 (LOVETT, 2013, p. 11).

Inspirado por Kant, Rousseau e Locke, John Rawls (2008) questionou as premissas do Utilitarismo e procurou estruturar uma teoria social racional, liberal e com equidade.

Curiosamente, Locke, Rousseau e Kant constavam na lista de livros proibidos pela Santa Sé, a 'Index Librorum Prohibitorum', cuja primeira lista foi criada em 1515 e que durou até 1966, quando possuía quatro mil obras proibidas (ALTMAN, 2021).

John Rawls adota em seu trabalho, ainda que com algumas importantes distinções, a teoria do contrato social defendido Rousseau (2010, p. 33), que visava o estabelecimento de uma igualdade que não seria possível naturalmente, pois "podendo ser desiguais em força ou gênio, se tornam todos iguais pela convenção e pelo direito".

A obra rawlsiana possui forte influência do pensamento kantiano (KANT, 2019), como o racionalismo metodológico na escolha dos princípios fundamentais, a lógica da ideia da escolha na posição original com equidade, a desnecessidade do fundamento teológico para a validade da moral, a autonomia da vontade como princípio da moral, a estabilidade do sistema como decorrência do princípio da justiça universal, o respeito à dignidade e ao ser humano como um fim em si mesmo e a rejeição do Utilitarismo como consequência direta do imperativo categórico.

Kant (2010, p. 163) já destacava que o "princípio supremo da doutrina da virtude” era agir de acordo com a concepção de que a máxima dos fins seja considerada uma lei universal, obedecida por todos, como respeitar o ser humano como um fim em si mesmo. 
Roberto Gargarella (2008, pp. 1 a 13) relembra que um dos objetivos da Teoria da Justiça de John Rawls também era refutar o Utilitarismo e o Intuicionismo, demonstrando que sua teoria era racional e moralmente mais sólida, adequada e plural.

A sociedade é marcada por identidade e conflitos de interesses: de um lado a melhoria de vida e proteção decorrente da cooperação social e, de outro, a divergência sobre os critérios de distribuição dos benefícios produzidos através dessa cooperação (RAWLS, 2008, p. 153).

Rawls (2008, pp. 154 e 155) denomina a identidade e o conflito de interesses como circunstâncias da justiça, que podem ser divididas duas: 1- circunstâncias objetivas, referentes à vulnerabilidade a agressões e a escassez moderada; e 2- circunstâncias subjetivas, relacionadas aos projetos de vida de cada indivíduo e as distintas reinvindicações sobre os recursos naturais e sociais disponíveis. As circunstâncias subjetivas também sofrem influências dos preconceitos, ansiedades, egoísmos e da diversidade de crenças religiosas, filosóficas, políticas e sociais.

Em relação à circunstância subjetiva da justiça, a justiça procedimental pura adotada por Rawls (2008, pp. 101 e ss.) procurará preservar o pluralismo moral dos integrantes da sociedade, possibilitando que cada indivíduo possa, com liberdade, escolher e seguir seus próprios objetivos de vida, inclusive com a garantia de igualdade equitativa de oportunidades.

Diante da concepção da sociedade como um sistema de cooperação criado para promover o benefício mútuo dos seus participantes, Rawls (2008, pp. 5, 73, 75) formulou os dois princípios de justiça que sustentavam sua teoria para a estruturação de uma sociedade justa:

Primeiro: cada pessoa deve ter um direito igual ao sistema mais extenso de iguais liberdades fundamentais que seja compatível com um sistema similar de liberdades para as outras pessoas.

Segundo: as desigualdades sociais e econômicas devem estar dispostas de tal modo que tanto (a) se possa esperar que se estabeleçam em benefício de todos como (b) estejam vinculadas a cargos e posições acessíveis a todos.

Rawls (2008, pp. 91 e 100), deixando claro que a estrutura social não deve garantir melhores perspectivas para quem já está em melhor situação, salvo se isso for vantajoso para os menos afortunados, complementa o enunciado do segundo princípio:

As desigualdades sociais e econômicas devem estar dispostas de tal modo que tanto (a) propiciem o máximo benefício esperado para os menos favorecidos como (b) estejam vinculadas a cargos e posições abertos a todos em condições de igualdade equitativa de oportunidades. 
Álvaro de Vita (2008, pp. 45 a 60) relembra que numa sociedade justa há também a necessidade da adoção de arranjos institucionais no sentido de que os benefícios decorrentes dos "talentos naturais" adquiridos por algumas pessoas sejam compartilhados com outros menos afortunados. Portanto, a justiça por equidade procurará mitigar as consequências das circunstâncias sociais e da sorte natural, pois "ninguém deve beneficiar-se dessas contingências, a não ser de maneira que redundem no bem-estar dos outros" e a preocupação da sociedade deve ser com aqueles com menor talento inato e aqueles oriundos de posições sociais menos favoráveis (RAWLS, 2008, pp. 119 e 120).

A expressão "princípio lexical da diferença" é utilizada para expressar a sequência ideal e preferencial de ganhos, iniciando pelo indivíduo representativo na pior posição, após aquele que estiver na segunda posição e assim por diante até o indivíduo na melhor situação (Rawls, 2008, p. 100). Reconhece, porém, que tal aplicação "princípio lexical da diferença" na prática é muito improvável. Assim procurará focar no primeiro passo, priorizando os ganhos dos menos afortunados.

Esses dois princípios de justiça se destinam principalmente à estrutura básica da sociedade e visam estabelecer os critérios para a atribuição de direitos e deveres e para a distribuição de vantagens sociais e econômicas.

Rawls (2008, p. 75) explica que todos os valores sociais, como liberdade, oportunidade e riqueza, "devem ser distribuídos de forma igual, a não ser que uma distribuição desigual de um ou de todos esses valores seja vantajosa para todos”.

O primeiro princípio garante o direito a liberdades fundamentais iguais, englobando a liberdade política, de expressão, de reunião, de consciência, bem como o direito à propriedade pessoal e à proteção contra prisões arbitrárias, enquanto que o segundo se destina a regular a distribuição de riqueza e o acesso amplo aos cargos de autoridade e de responsabilidade (RAWLS, 2008, p. 74).

Os dois princípios estabelecidos também são aplicados em "ordem serial ou léxica", ou seja, o primeiro princípio, o da liberdade igual, deve ser aplicado prioritariamente sobre o segundo, que estabelece critério para a existência de desigualdades sociais e econômicas. Assim, a "ordenação em série evita, então, a necessidade de equilibrar princípios" (RAWLS, 2008, p. 52).

Assim, o primeiro princípio não pode ser limitado pelo segundo princípio, visto que as liberdades fundamentais somente podem ser restringidas quando houver conflito com outras 
liberdades fundamentais, não sendo possível sua redução em razão de questões relacionadas com a distribuição de renda e riqueza, por exemplo.

É possível perceber, desta forma, que para a justiça como equidade não é aceitável ou justa a adoção de medidas que diminuam a desigualdade social ou econômica ou que aumentem os ganhos econômicos mediante redução de liberdades fundamentais.

Coerente com a ordem serial ou léxica de princípios, Rawls (2008, p. 244) propõe que o primeiro princípio, da liberdade igual, seja protegido através da convenção constituinte e o segundo princípio, da igualdade equitativa de oportunidade, seja estabelecido num momento imediatamente posterior, no denominado "estágio legislativo".

Mister esclarecer que a ordem serial ou léxica utilizada por Rawls na aplicação dos dois princípios da justiça (em que o primeiro princípio da ampla liberdade tem prioridade absoluta sobre o segundo princípio da diferença e do amplo acesso aos cargos de responsabilidade) é distinta da ordem serial ou léxica utilizada em relação ao princípio da diferença, em que a sequência ideal de "vantajosidade" deve partir da classe mais desfavorecida para a classe subsequente e assim sucessivamente. Enquanto que a ordem serial ou léxica dos dois princípios da justiça é pressuposto fundamental da teoria rawlsiana, a ordem serial ou léxica da diferença é apenas um ideal muito improvável na distribuição de vantagens aos diferentes grupos sociais, dos mais necessitados aos mais abastados.

A exigência de que a abertura de cargos e posições a todos em condições de igualdade evita o sentimento de injustiça dos excluídos, ainda que pudessem se beneficiar dos esforços daqueles que estão autorizados a ocupá-los (RAWLS, 2008, P. 102). Trata-se, evidentemente, de garantia às legítimas expectativas, beneficiando todos os integrantes do conjunto social e que devem cooperar para o bem comum.

Para Rawls (2008, pp. 18 e 75), não há injustiça em benefícios maiores recebidos por alguns, desde que tal situação melhore a situação das pessoas menos afortunadas, pois a injustiça reside em desigualdades que não sejam benéficas para todos. De fato, na Teoria da Justiça de Rawls, a "concepção geral da justiça não impõe restrições quanto aos tipos de desigualdade permissíveis; ela só exige que a situação de todos melhore”.

A vantajosidade para os menos favorecidos é elemento central na concepção de uma sociedade justa para Rawls (2008, p. 286).

Sempre que houver uma desigualdade na estrutura básica, deve-se justificala para os que estão na posição mais desvantajosa. Isso vale para qualquer um dos bens sóciais primários e, em especial, para a liberdade. Portanto, a regra de 
prioridade exige que mostremos que a desigualdade de direitos seria aceita pelos menos favorecidos em troca da maior proteção, resultante dessa restrição, de suas outras liberdades.

Os princípios de justiça têm cinco características essenciais para Rawls (2008, pp. 159 a 164): generalidade, universalidade, publicidade, ordenação e finalidade:

- Por generalidade deve-se entender que os princípios de justiça não devem ser formulados especificamente a determinadas pessoas ou grupos, lembrando-se que todos devem desconhecer, por trás do véu de ignorância, informações específicas sobre si e sobre a situação social antes da escolha dos princípios da justiça;

- A universalidade expressa a incompatibilidade de exceções com os princípios acolhidos por todos os integrantes do grupo social. A universalidade não pode ser confundida com a generalidade, como no exemplo da ditadura, que pode corresponder à universalidade, mas não à generalidade;

- A publicidade é uma presunção de "que todos saberão desses princípios", ou seja, de que os princípios da justiça não só foram escolhidos de forma consciente, voluntária e numa situação de equidade, mas também são regularmente seguidos por todos. Neste aspecto, o modelo de justiça substantiva proposto procura ser o mais próximo de um sistema social voluntário, pois os integrantes do respectivo grupo social estariam de acordo, dentro de um pensamento racional, com a estrutura social proposta e com as expectativas traçadas;

- A ordenação objetiva é essencial para dirimir as reinvindicações conflitantes dos integrantes do grupo social, tornando-se desnecessário o recurso à força e distinguindo a justiça como equidade do intuicionismo; e

- A finalidade consiste na inexistência de uma nova chance de escolha, conforme sua conveniência, dos princípios da justiça, das instituições e do próprio sistema social.

A característica da ordenação objetiva é uma das grandes distinções da justiça com equidade do intuicionismo (RAWLS, 2008, pp. 47, 49, 50 e 54).

Já a generalidade distingue a justiça como equidade do utilitarismo, pois nesta teoria as minorias podem ser submetidas, contra sua vontade, a inúmeras restrições a direitos e interesses em benefício de uma determinada maioria. A finalidade também é uma característica que distingue as duas teorias, pois no utilitarismo as pessoas mais vulneráveis e prejudicadas pelo sistema social imposto, diante de restrições excessivas a que são submetidas, algumas insuportáveis e indignas, tem a tendência de rejeitar o princípio de moralidade escolhido (maximização da satisfação e da felicidade). 
De fato, no utilitarismo as obrigações e restrições impostas ao grupo menos afortunado dificilmente são cumpridas de forma voluntária, exigindo-se forte ideal de compaixão e benevolência (RAWLS, 2008, pp. 177, 215, 216 e 218).

No mesmo sentido do critério de finalidade, a publicidade também é observada de forma distinta pelo utilitarismo e pela teoria rawlsiana, pois, enquanto que na justiça como equidade todos os integrantes do grupo social devem conhecer os princípios da justiça escolhidos, no utilitarismo essa publicidade é extremamente restrita, visto que não há fortes argumentos racionais para justificar as enormes restrições impostas aos mais desafortunados, exceto os ideais de compaixão e benevolência em prol dos mais afortunados.

Os princípios de justiça propostos por Rawls não só constituem o alicerce da estrutura básica da sociedade, como também servem como parâmetro independente de avaliação da produção de normas constitucionais justas e eficazes e do consequente arcabouço legislativo necessários para se atingir o resultado pretendido pela justiça como equidade, tanto de ampla garantia de liberdade igual, quanto da igualdade democrática que deve ampliar as expectativas dos menos afortunados (RAWLS, 2008, p. 242 e 243).

Rawls (2008, p. 307) ensina que a exequibilidade da ordem lexical dos princípios depende, em certo grau, das circunstâncias sociais existentes, devendo os legisladores constituinte e ordinário observarem tais circunstâncias com o escopo de maximizar os dois princípios de justiça, especialmente para os menos favorecidos.

É importante ressaltar que, sob o ponto de vista moral, o uso da força não pode ser aceito como parâmetro de escolha dos princípios da justiça e na formação de uma sociedade verdadeiramente moral, pois se presume que "a ideia de 'a cada um segundo a sua capacidade de ameaça' não é uma concepção de justiça” (RAWLS, 2008, p. 163).

Há concordância com Aristóteles quanto à rejeição da 'pleonexia' na sua concepção de justiça, ou seja, a necessidade de que não se tome, indevidamente, algo pertencente a outrem para obtenção de vantagem própria ou de que se negue a alguém o que lhe é devido (RAWLS, 2008, p. 12).

É importante reiterar que para Rawls (2008, p. 17), o Utilitarismo é inaceitável dentro de uma sociedade concebida como um sistema cooperativo destinado a promover o bem de todos os seus integrantes, pois é esse sistema permite o sacrifício de minorias para a maximização da felicidade dos demais. 
Sobre os bens primários, Rawls (2008, p. XXXVIII) explica que "são agora caracterizados como aquilo de que elas precisam em seu status de cidadã livres e iguais e de membros normais e plenamente cooperativos da sociedade durante toda a vida".

Os indivíduos deverão cumprir suas obrigações e deveres quando as instituições respeitarem os dois princípios de justiça e que as pessoas tenham aceitado livremente os benefícios do arranjo social ou tirado proveito das oportunidades ofertadas, pois "não devemos lucrar com os esforços cooperativos de outrem sem ter contribuído com nossa quota justa” (RAWLS, 2008, p. 134).

\subsection{O esquema plenamente adequado de liberdades fundamentais}

Rawls (2008, pp. 247 e 248) qualifica a liberdade através de três elementos: "agentes que são livres, as restrições ou limitações de que estão livres e aquilo que tem liberdade para fazer ou não fazer".

Nesse mesmo sentido, novamente Rawls (2008, p. 248):

A descrição geral de qualquer liberdade, então, assume a seguinte forma: esta ou aquela pessoa (ou pessoas) está (ou não está) livre desta ou daquela restrição (ou conjunto de restrições) para fazer (ou não fazer) isto ou aquilo. [...] Nesse contexto, os indivíduos tem liberdade para fazer alguma coisa quando estão livres de certas restrições, quer para fazê-la, quer para não fazê-la, e quando o ato de fazê-la ou não fazê-la está protegido contra a interferência de outras pessoas.

O valor incomensurável da liberdade também tem fundamento histórico, como bem apontado por Rawls (2008, pp. 258 e 259):

A história demonstra que os homens desejam ser livres sempre que não tenham se resignado à apatia e ao desespero, ao passo que aqueles que são livres jamais querem abdicar da liberdade. Embora os homens possam queixar-se dos fardos da liberdade e da cultura, têm um desejo maior de decidir como devem viver e de resolver seus próprios problemas.

Rawls (2008, p. 251) reconhece que as observações sobre o conceito de liberdade são abstratas e que "de nada serviria classificar sistematicamente as diversas liberdades", mas destaca a fundamentalidade da liberdade de consciência, a liberdade de pensamento, a liberdade política e a liberdade individual.

Para a justiça como equidade, uma liberdade somente pode ser limitada em nome da própria liberdade, apesar de inexistir um "critério preciso para definir quando temos justificativa para restringir uma liberdade, seja ela fundamental ou não" (RAWLS, 2008, p. 250 e 252$)$. 
A limitação de liberdades fundamentais em razão da necessidade proteção de outras liberdades fundamentais, da ordem pública e do interesse comum, está em harmonia com o pensamento rawsiano, como no caso da liberdade de consciência (RAWLS, 2008, p. 262):

\begin{abstract}
Restringir a liberdade de consciência dentro dos limites, por mais imprecisos que sejam, dos interesses do Estado na ordem pública é uma limitação derivada do princípio do interesse comum, ou seja, o interesse do cidadão representativo. O direito do Estado de manter a ordem e a segurança públicas é um direito de capacitação, um direito que o Estado deve ter para ser capaz de cumprir com seu dever de apoiar imparcialmente s condições necessárias para que todos possam promover seus interesses e cumprir suas obrigações segundo seu entendimento delas.

Além disso, a liberdade de consciência só deve ser limitada quando há uma expectativa razoável de que não fazê-lo prejudicará a ordem pública que o Estado deve manter. Essa expectativa deve basear-se em evidências e formas de argumentar que são aceitáveis para todos.
\end{abstract}

Assim, “o único fundamento para negar as liberdades iguais é evitar uma injustiça ainda maior, uma perda ainda maior de liberdade" (RAWLS, 2008, p. 264).

As liberdades, de fato, podem ter menor extensão para a preservação das próprias liberdades, como no caso da liberdade política combinada com a existência de mecanismos como o legislativo bicameral, separação de poderes e controle jurisdicional de constitucionalidade (RAWLS, 2008, pp. 276 e 277). Tais mecanismos de limitação dos poderes do Estado e da própria liberdade individual política buscam garantir, sem sombra de dúvidas, a própria liberdade fundamental individual, especialmente das minorias.

De qualquer forma, o primeiro princípio da justiça de Rawls já citado garante o direito a um amplo esquema de liberdades fundamentais iguais, englobando a liberdade política, de expressão, de reunião, de consciência, bem como o direito à propriedade pessoal e à proteção contra prisões arbitrárias, enquanto que o segundo se destina a regular a distribuição de riqueza e o acesso amplo aos cargos de autoridade e de responsabilidade. A especificação completa das liberdades fundamentais depende das "circunstâncias sociais, econômicas e tecnológicas específicas de cada sociedade" (RAWLS, 2008, pp. 74 e 75).

Além disso, Rawls (2008, pp. 250 e 251) salienta o impacto da questão social e econômica no gozo das liberdades:

A incapacidade de beneficiar-se dos próprios direitos e das próprias oportunidades em consequência de pobreza e ignorância e a falta de recursos em geral às vezes se incluem ente restrições que são definidoras da liberdade. [...] o valor da igualdade não é igual para todos. Alguns têm mais autoridade e riqueza e, portanto, mais recursos para atingir seus objetivos. 
Diante da desigualdade no gozo das liberdades fundamentais em razão de questões sociais ou econômicas, torna-se necessário garantir compensações para as classes menos afortunadas (RAWLS, 2008, p. 251):

Considerando-se os dois princípios em conjunto, a estrutura básica deve ser organizada de forma a maximizar o valor para os menos favorecidos do sistema de liberdade igual compartilhado por todos. Isso é o que define o objetivo da justiça social.

Assim, apesar da prioridade absoluta do primeiro princípio, que garante a cada pessoa “direito igual ao sistema mais extenso de iguais liberdades fundamentais que seja compatível com um sistema similar de liberdades para as outras pessoas", Rawls (2011, pp. 386 e 387) deixa claro que ambos os princípios (da liberdade e da igualdade democrática) precisam estar intimamente conectados, com o escopo de garantir que as liberdade fundamentais não sejam meramente formais:

Não há dúvida de que a ignorância e a pobreza e a falta de meios materiais, de modo
geral, impedem as pessoas de exercer seus direitos e tirar proveito dessas
oportunidades. [...] na justiça como equidade, as liberdades fundamentais são as
mesmas para cada cidadão, e não se apresenta a questão sobre como compensar uma
menor liberdade. Mas o valor ou o proveito que se é capaz de tirar da liberdade não
é o mesmo para todos. Na medida em que isso é permitido pelo princípio da
diferença, alguns cidadãos terão, por exemplo, renda e riqueza maiores e, por isso,
disporão de meios maiores para realizar seus fins. No entanto, quando esse princípio
é satisfeito, esse valor menor da liberdade é compensado no seguinte sentido: os
meios polivalentes disponíveis para os membros menos privilegiados das sociedades
seriam ainda menores caso as desigualdades sociais e econômicas, medidas pelo
índice de bens primários, fossem diferentes do que são pelo princípio da diferença.
A estrutura básica da sociedade é organizada de tal maneira que eleva ao nível
máximo os bens primários disponíveis aos menos privilegiados, de maneira que
sejam capazes de fazer uso das liberdades fundamentais iguais desfrutadas por
todos. Isso define um dos objetivos centrais da justiça política e social.

Parece interessante mencionar a importância que Rawls (2011 pp. 385 e 388) dava para o distanciamento dos partidos políticos das grandes concentrações de riqueza e partidos políticos, pois o controle do processo político pelos grandes poderes econômicos e sociais é extremamente nocivo para o combate às desigualdades e para a estruturação de uma sociedade substancial e efetivamente justa:

Foram muitos os que argumentaram, sobretudo democratas radicais e socialistas, que, embora possa parecer que os cidadãos são efetivamente iguais, as prováveis desigualdades sociais e econômicas que se produzirão, caso a estrutura básica garanta liberdades fundamentais e a igualdade equitativa de oportunidade, serão demasiado grandes. Aqueles que têm responsabilidade e riqueza maiores conseguem controlar o processo legislativo em seu benefício. [...] Mas uma recomendação para garantir o valor equitativo parece ser manter os partidos políticos independentes das grandes concentrações do poder econômico e social privado, em uma democracia com propriedade privada de recursos produtivos, e do controle estatal e do poder burocrático, em um regime socialista liberal. Em ambos os casos, a sociedade deve 
arcar pelo menos com grande parte do custo de organizar e realizar o processo político e deve regular a condução das eleições. A garantia do valor equitativo das liberdades políticas é uma das formas pelas quais a justiça como equidade procura responder à objeção de que as liberdades fundamentais são meramente formais.

De fato, é essencial que haja ampla distribuição de propriedade e riqueza e independência dos partidos políticos em relação aos poderes econômicos privados, pois o uso abusivo das vantagens econômicas e sociais possuídas pelas classes mais abastadas para controle do debate público destruirá os próprios princípios de justiça, aumentando e consolidando a desigualdade social. É também necessário destacar que, diante do controle do processo político pelas classes mais abastadas através do uso de suas vantagens econômicas e sociais, "os membros menos favorecidos da sociedade impedidos de exercer seu grau equitativo de influência devido à carência de recursos, se fecham na apatia e ressentimento" (Rawls, 2008, pp. 278 e 279).

Ainda em relação às liberdades fundamentais, parece importante destacar que Rawls (2008, p. 75) não considera todos os tipos de propriedade fundamentais e protegidos pelo primeiro princípio. Em regra, o que se protege no primeiro princípio é a propriedade pessoal, não aquela relacionada, por exemplo, com os meios de produção. Nesse sentido, em regra, a propriedade intelectual também não é considerada fundamental e não está protegida pelo primeiro princípio.

\subsection{A igualdade democrática}

Para explicar o segundo princípio e interpretar as expressões "benefício de todos" e "acessíveis a todos", Rawls abordará quatro interpretações distintas: o sistema de liberdade natural, a aristocracia natural, a igualdade liberal e a igualdade democrática.

O sistema de liberdade natural é caracterizado como um sistema social aberto em que as carreiras estão abertas aos talentos através de uma igualdade formal de oportunidades, correspondendo, grosso modo, a um sistema de livre mercado. Nesse sistema, apesar da distribuição inicial de recursos sofrer forte impacto das contingências naturais e sociais, não há maiores esforços em se buscar uma maior igualdade substancial (RAWLS, 2008, p. 80 e 87).

Por sua vez, o sistema de igualdade liberal tenta buscar uma maior igualdade de oportunidades, garantindo mecanismos estruturais que propiciem que pessoas com mesmo nível de talentos e capacidade tenham as mesmas oportunidades, independentemente da sua 
origem no sistema social. Apesar de ser preferível ao sistema de liberdade natural, a igualdade liberal não evita que a desigualdade na distribuição de riquezas ocorra em razão da "loteria natural". Para Rawls, o resultado decorrente de uma loteria natural de talentos é arbitrário do ponto de vista moral. (2008, pp. 88 e 89).

Ainda em relação à igualdade liberal, Rawls (2008, p. 89) também relembra o impacto das estruturas familiares no desenvolvimento das aptidões naturais, vulnerando o sistema de incentivo à igualdade entre mesmos talentos e capacidades.

Já o sistema de aristocracia natural não procura limitar ou regular a arbitrariedade da contingência social inicial e que "a situação melhor daqueles que são favorecidos por esse sistema só é considerada justa quando aqueles que estão em situação inferior ficariam com ainda menos caso as vantagens dos primeiros fossem reduzidas" (RAWLS, 2008, pp. 89 e 90).

Sobre a meritocracia, Rawls deixa claro que, moralmente, ninguém pode se julgar merecedor de benefícios decorrentes de fatos naturais ou sociais arbitrários, que fogem do seu próprio controle (2008, p. 18):

Os dois princípios mencionados aparentam ser uma base equitativa sobre a qual os mais favorecidos por talento natural, ou os mais afortunados em posição social, duas coisas das quais não nos podemos considerar merecedores, possam esperar a cooperação voluntária dos outros quando algum sistema viável seja uma condição necessária para o bem-estar de todos.

Partindo do pressuposto de que, do ponto de vista moral, a loteria natural de talentos e a fortuna social são arbitrários, Rawls (2008, p. 90) adotará a interpretação democrática do segundo princípio, refutando a justiça na distribuição de riqueza e no acesso aos cargos de autoridade e de responsabilidade a partir desses eventos arbitrários:

Uma vez que tentemos encontrar uma interpretação que trate a todos igualmente como pessoas morais, e que não meça a parcela de cada pessoa nos benefícios e nos encargos da cooperação social segundo sua fortuna social ou sua sorte na loteria natural, a interpretação democrática aparecerá como a melhor escolha dentre as quatro opções.

Por sua vez, Álvaro de Vita (2008, p. XXII) relembra que não é justo que as perspectivas de vida das pessoas sejam determinadas meramente por circunstâncias aleatórias sociais ou genéticas:

[...] uma sociedade que objetiva assegurar essa forma de igualdade humana fundamental em suas instituições sociais e políticas não pode permitir que as perspectivas de vida de seus membros sejam determinadas pelo ocaso social ou genético. [...] não é justo que, em uma sociedade democrática, as pessoas sofram os 
efeitos de fatores que respondem pela produção de desigualdades socioeconômicas e que estão fora do seu próprio controle.

A interpretação democrática buscará, de um lado, evitar incentivos adicionais às arbitrariedades sociais e naturais e, de outro, combinar o princípio da igualdade equitativa de oportunidades com o princípio da diferença, através de uma estrutura de instituições que garantam a liberdade igual e a igualdade equitativa de oportunidades a todos, indistintamente. O princípio da diferença terá como foco principal melhorar a situação dos menos afortunados (RAWLS, 2008, pp. 91 e 96).

Sandel (2014, pp. 189 e 190) exemplifica os pressupostos estabelecidos por Rawls para que a desigualdade seja aceitável e justa:

O que dizer do alto salário de Michael Jordan ou da grande fortuna de Bill Gates? Essas desigualdades seriam coerentes com o princípio da diferença? Evidentemente, a teoria de Rawls não tem como objetivo avaliar se o salário dessa ou daquela pessoa é justo; ela se refere à estrutura básica da sociedade e à forma como ela distribui direitos e deveres, renda e fortuna, poder e oportunidades. Para Rawls, a questão é saber se a fortuna de Gates é parte de um sistema que, como um todo, trabalha em benefício dos menos favorecidos. Por exemplo, sua fortuna está sujeita a um sistema progressivo de impostos sobre a renda do rico com o objetivo de favorecer a saúde, a educação e o bem estar do pobre? Em caso positivo, e se esse sistema melhorou as condições do pobre em relação ao que elas poderiam ter sido em um regime mais rigoroso de distribuição de renda, então essas desigualdades seriam coerentes com o princípio da diferença.

Rawls (2008, p. XL e XLI) esclarece que sua teoria não pode ser confundida com a ideia de bem-estar social, visto que nesta ideia não há preocupação em dispersar a propriedade de riquezas e capital e em impedir que uma pequena parte da sociedade controle a economia e a vida política. O estado de bem-estar social tem como objetivo manter padrão de vida razoável para todos mediante o recebimento de determinadas proteções sociais, não havendo grande preocupação em estabelecer mecanismos que impeçam a acumulação de grandes desigualdades de riquezas, inclusive hereditárias, o que acaba tornando a equidade de oportunidades ineficaz diante das enormes disparidades de riqueza e de poder político.

Diferentemente do utilitarismo, a justiça como equidade não admite que diferenças de renda e de posições de autoridade e responsabilidade sejam justificadas através do argumento de que as desvantagens de uns são compensadas com as vantagens de outros.

Rawls (2008, p. 81) adota como princípio de eficiência o parâmetro contido na "otimalidade de Pareto":

O princípio afirma que determinada configuração é eficiente sempre que é impossível modificá-la para melhorar a situação de algumas pessoas (pelo menos uma) sem, ao mesmo tempo, piorar a situação de outras pessoas (pelo menos uma). 
[...] A distribuição de bens ou um sistema de produção será ineficiente quando houver meios de melhorar ainda mais a situação de alguns indivíduos sem piorar a de outros. Vou presumir que as partes, na posição original, aceitam esse princípio para avaliar a eficiência de arranjos econômicos e sociais.

Porém, para a justiça como equidade, é necessário adequar a "otimalidade de Pareto" ao segundo princípio estabelecido por Rawls (2008, pp. 73 e 100). O gráfico 1 abaixo demonstra que, apesar da situação 2 ser compatível com a "otimalidade de Pareto", ou seja, com uma sensível melhora da classe mais favorecida sem a piora da classe menos favorecida, tal situação é incompatível com a justiça como equidade, por não representar qualquer para situação dos menos afortunados.

\section{Gráfico 1}

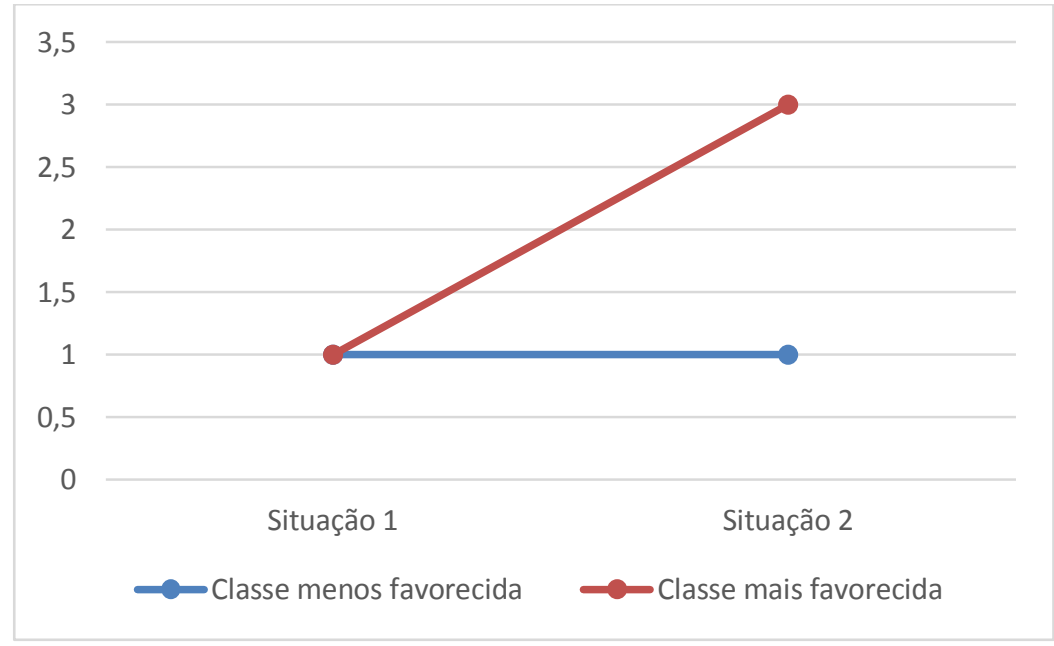

Ainda no gráfico 1, parece importante perceber que sob o ponto de vista da máxima eficiência, no cenário 2 é considerado melhor que o primeiro.

A situação inversa, com melhoria apenas da classe menos favorecida sem prejuízo dos mais afortunados, é admissível pela justiça como equidade, mas não representa o "esquema perfeitamente justo", em que há melhora de todas as classes (RAWLS, 2008, p. 95).

Rawls complementa, declarando que, em regra, todos os valores sociais "devem ser distribuídos de forma igual, a não ser que uma distribuição desigual de um ou de todos esses valores seja vantajosa para todos" (2008, p. 73).

Já o gráfico 2 abaixo demonstra 3 situações e 3 classes distintas, em que o primeiro cenário demonstra uma igualdade absoluta entre todas as classes, o segundo um ganho de todas as classes e o terceiro um ganho apenas das duas classes superiores (apesar de inexistir prejuízo para a classe menos favorecida). 
Nesse gráfico 2, a justiça como equidade adotará a situação 2, em que todas as classes estão em melhor situação que na primeira situação, ainda que as duas classes mais afortunadas tenham tido um ganho mais expressivo. Todavia, a justiça como equidade rejeitará a situação 3, em que a classe mais desfavorecida não terá ganho algum, ainda que a situação represente uma melhoria do ponto de vista da mera eficiência econômica.

O utilitarismo, desde que as duas classes mais favorecidas representem a maioria dos envolvidos na sociedade, aceitará a situação 3 do gráfico 2 .

\section{Gráfico 2}

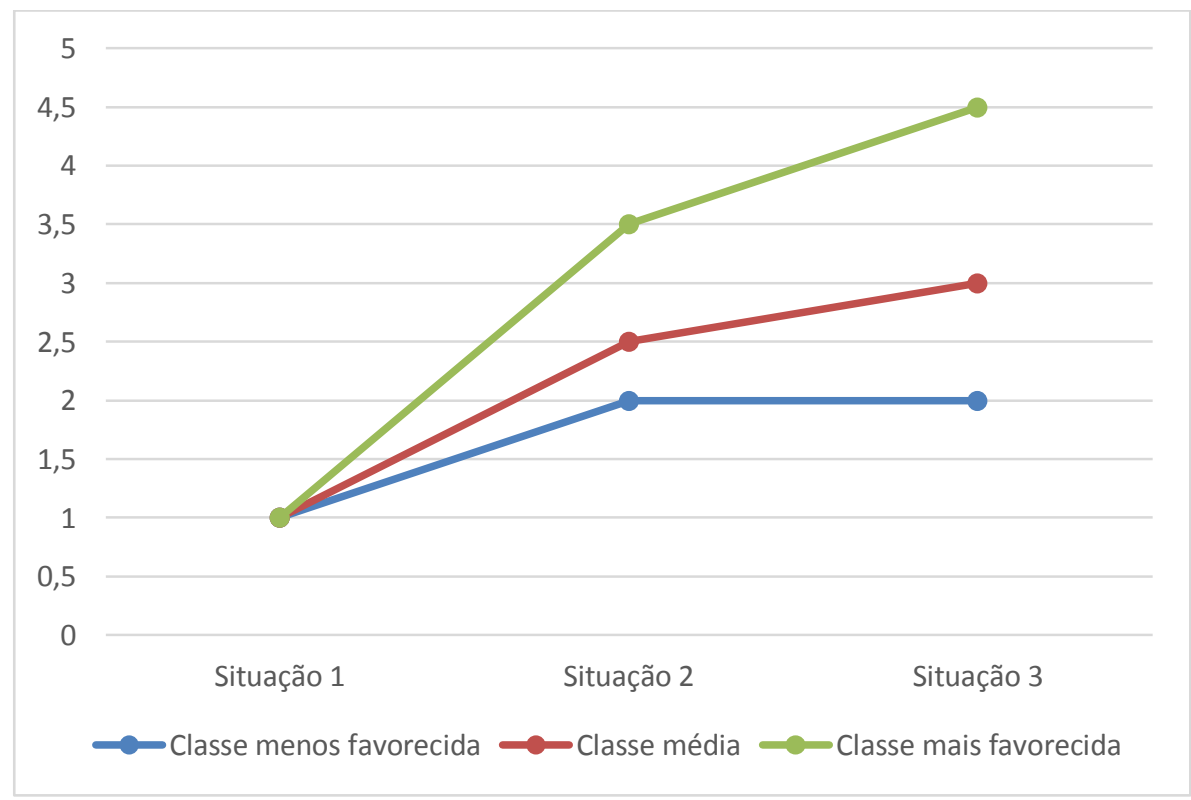

Em que pese a existência de pensamentos que dão prioridade absoluta à igualdade absoluta, Rawls (2008, p. 173) defende que as pessoas racionais sempre vão querer ter mais, e não menos, bens primários sociais para conseguirem ter maiores chances de atingirem seus objetivos de vida, pois "sabem que, em geral, devem tentar proteger suas liberdades, ampliar suas oportunidades e os meios de promover seus objetivos, quaisquer que sejam".

Rawls (2008, pp. 174 e 175) também rejeita a inveja como elemento do pensamento racional, não admitindo, desta forma, que pessoas racionais prefiram ter menos para que outras também tenham menos ou que fiquem deprimidas com a mera possibilidade de outras pessoas poderem ter mais bens primários sociais. Nesse exato sentido, não se aceita, sob uma perspectiva racional, que uma pessoa decida abandonar seus objetivos de vida somente para prejudicar ou dificultar os objetivos de vida das demais pessoas.

Para Rawls (2008, p. 175), “a concepção de justiça elimina as condições que dão origem a comportamentos destrutivos". 
Parece importante destacar que Rawls (2008, pp. 109 e 110), para a aplicação do princípio da diferença e para fins comparativos, em primeiro lugar adotará o método de escolha do 'indivíduo representativo' de cada grupo, para que possa identificar de que ponto deve-se julgar o sistema social, e, sem segundo lugar, definir a questão dos bens primários sociais, como quaisquer coisas que um indivíduo racional pretende e a categoria ampla de direitos, liberdades, oportunidades, renda e riqueza.

Bem, esclarece Rawls (2008, p. 111), “é a satisfação do desejo racional”.

Em relação ao indivíduo representativo, Rawls (2008, p. 114) deixa claro que nem todas as posições sociais são relevantes. Assim, "as posições sociais relevantes são, por assim dizer, os pontos de partida generalizados e agregados de uma forma apropriada".

Rawls (2008, pp. 117 e 118) reconhece que é impossível evitar certa discricionariedade na identificação do grupo menos afortunado, seja pelo seu posicionamento social, seja pelo seu posicionamento de renda e riqueza, mas que é essencial se analisar o sistema social de uma posição de cidadania e dos diversos níveis de renda e riqueza.

Algumas outras posições podem ser levadas em conta as vezes, como diferenças baseadas em sexo, raça e cultura, mas tais "desigualdades raramente trazem, se é que chegam a trazer, vantagens para os menos favorecidos e, por conseguinte, numa sociedade justa, o menor número de posições relevantes deveria bastar” (RAWLS, 2008, p. 118).

\section{IMPACTOS NA QUESTÃO DA EFICIÊNCIA ECONÔMICA}

Rawls (2008, p. 189) deixa claro que a justiça como equidade é plenamente compatível com as exigências razoáveis de eficiência, mas os sistemas de eficácia econômica não podem estar desvinculados dos princípios de justiça e das questões morais.

Como já mencionado, Rawls (2008, p. 81) adota a "otimalidade de Pareto" como princípio de eficiência, em que uma situação é considerada eficiente quando houver a possibilidade de melhora de uma ou mais pessoas sem que haja piora na situação de outra(s) pessoa(s). Todavia, deve-se adequar a "otimalidade de Pareto" ao segundo princípio estabelecido por Rawls (2008, pp. 73 e 100), visto que não se admite, por exemplo, a melhora da classe mais abastada sem que a classe menos afortunada seja beneficiada, não sendo suficiente, a ausência de prejuízo dessa classe mais necessitada. 
O gráfico 3 adiante representa a mesma situação do gráfico 2, mas é apresentado de uma forma diferente para melhor visualização dos quantitativos máximos de cada uma das 3 situações, ou seja, para melhor visualizar a questão da máxima eficiência.

Desta forma, sob o ponto de vista da máxima eficiência e da otimalidade de Pareto, a situação 3 (maior soma total, configurando o melhor cenário para as classes média e alta, sem prejuízo da classe baixa) é melhor que a situação 2 (soma total menor que a situação 3 , sem prejuízo de nenhuma classe), que por sua vez é melhor que a situação 1, em que há uma igualdade absoluta entre todas as classes e soma total inferior aos demais cenários.

O utilitarismo também aceitará a situação 3 como melhor hipótese, desde que as duas classes mais favorecidas representem a maioria dos envolvidos na sociedade.

\section{$\underline{\text { Gráfico } 3}$}

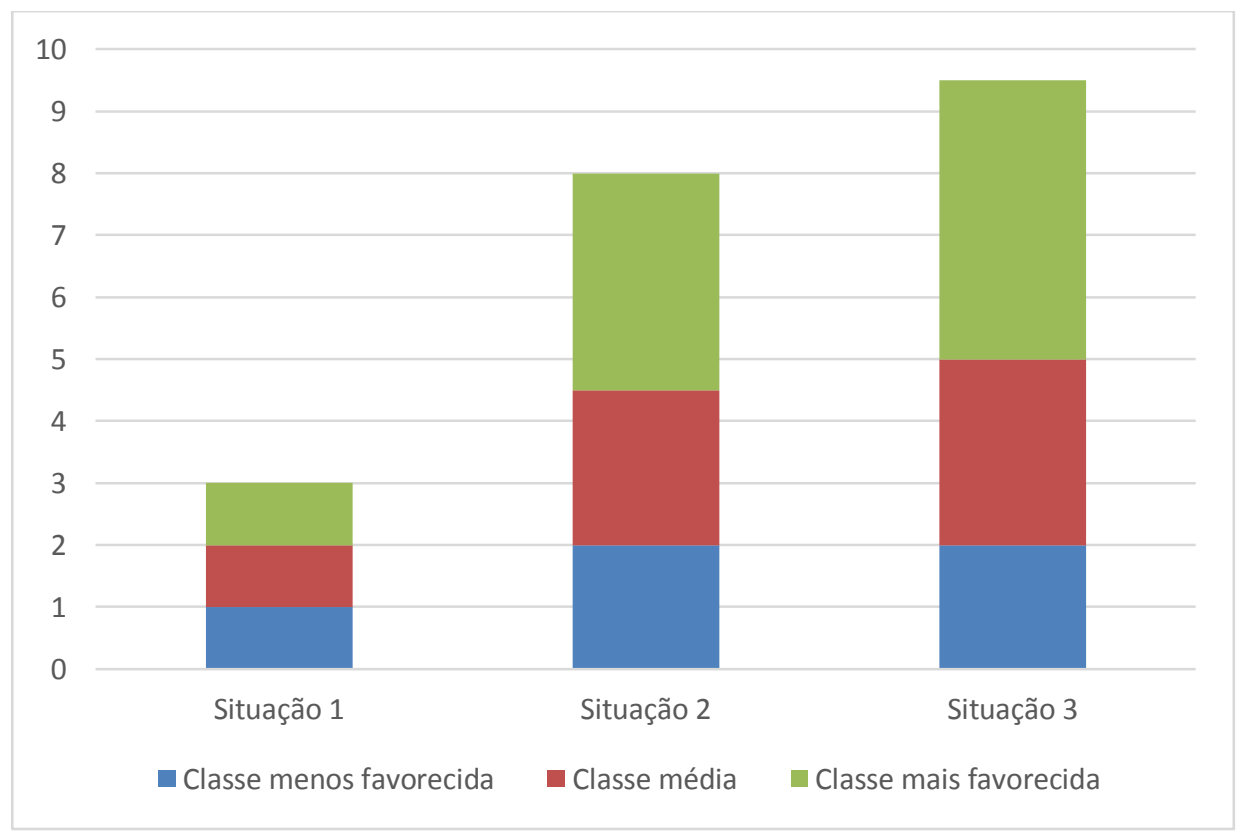

Porém, a situação 2 do gráfico 3 é o cenário para a justiça como equidade, em que todas as classes estão em melhor situação em relação à primeira situação. A situação 3 , em que a classe mais desfavorecida não terá ganho algum, é inaceitável para a justiça como equidade, ainda que tal situação represente uma melhoria do ponto de vista da máxima eficiência econômica.

Rawls (2008, p. 38) deixa claro que a característica principal da justiça como equidade é de que o justo tem prioridade sobre o bem e que "os desejos e aspirações individuais são restringidos desde o início pelos princípios de justiça que especificam os limites que os sistemas humanos de objetivos devem respeitar". 
Nesse mesmo sentido, Rawls (2008, p. 84) declara que "na justiça como equidade os princípios de justiça têm prioridade sobre considerações de eficiência”. Assim, critérios justos de distribuição devem prevalecer sobre critérios estritos de eficiência.

Bittar e Almeida (2012, p. 451) relembram que os sistemas econômicos não devem estar desvinculados da ideia de justiça:

E, ainda que haja fortes traços de economicidade em suas proposições teóricas, o que se há de dizer é que também qualquer sistema econômico está baseado em uma ideia de justiça. Isso porque, devemos dizer desde já, não há justiça sem moral, política ou economia, para Rawls.

De fato, os sistemas econômicos não devem estar desvinculados da ideia de justiça e de um sistema social considerado justo. O gráfico 4, por exemplo, representa situações que são indiferentes do ponto de vista da máxima eficiência econômica, pois a soma total de cada uma das 4 situações é a mesma, seja de uma igualdade absoluta retratada na situação 1, seja de absoluto domínio de uma só classe retratada na situação 4 (RAWLS, 2008, p. 83).

\section{Gráfico 4}

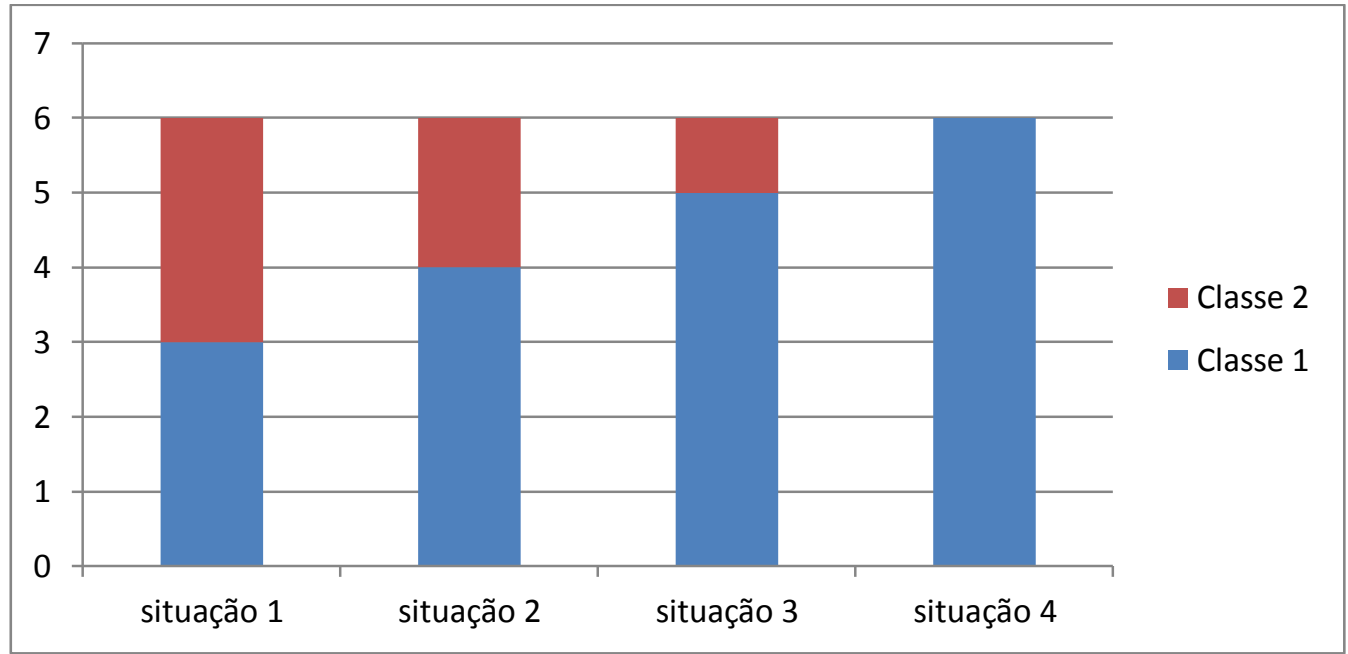

Rawls é enfático ao declarar que "o princípio da eficiência não pode servir sozinho como concepção de justiça”.

Para a justiça como equidade, dentre as 4 situações apresentadas, a $1^{\text {a }}$ é a única aceitável, pois reflete uma igualdade, enquanto que as demais situações expõem um ganho apenas de uma classe em detrimento da outra, pois "se não houver uma distribuição que melhore a situação de ambas as pessoas [...], deve-se preferir a distribuição igualitária" (RAWLS, 2008, p. 91).

Rawls (2008, pp. 101 e 186) também utilizará o critério econômico "maximin" para demonstrar que, por trás de um véu de ignorância, em que se desconhecem as particularidades 
de sua situação social e econômica, as pessoas procurarão identificar, dentre as possibilidades disponíveis, a alternativa que não seja pior que as demais:

Isso fica evidente a partir do fato de que os dois princípios são os que uma pessoa escolheria para a moldagem de uma sociedade na qual seu lugar fosse atribuído por seu inimigo. A regra maximin determina que classifiquemos as alternativas partindo dos piores resultados possíveis: devemos adotar a alternativa cujo pior resultado seja superior aos piores resultados das outras.

O critério maximin assegura a escolha de um modelo social em que, por pior que seja a situação inicial de uma pessoa nessa sua sociedade, os princípios, regras e instituições estabelecidas poderão ser obedecidos de forma consciente, voluntária e sem sacrifícios absurdos e não razoáveis, assegurando-se, desta forma, a própria estabilidade do sistema.

\section{CONSIDERAÇÕES FINAIS}

Os dois princípios propostos por John Rawls, defendendo a maximização das liberdades fundamentais e exigindo que as desigualdades econômicas e sociais sejam reguladas de forma a garantir maiores vantagens e oportunidades especialmente para os menos afortunados, são fundamentais para a construção de uma sociedade democrática e justa, um verdadeiro sistema de cooperação destinado a promover o benefício mútuo de todos os seus participantes.

A Teoria de Justiça de John Rawls também procurará preservar o pluralismo moral da sociedade contemporânea, possibilitando que cada indivíduo possa, com ampla liberdade, escolher e seguir seus próprios objetivos de vida, inclusive com a garantia de igualdade equitativa de oportunidades.

Ademais, é pertinente a preocupação de Rawls com a necessidade de que haja ampla distribuição de propriedade e riqueza e independência dos partidos políticos em relação aos poderes econômicos privados para a efetiva implantação dos próprios princípios de justiça e para o combate à desigualdade social. A justiça como equidade, de fato, não admite o controle do processo político pelas classes mais abastadas através do uso (e abuso) de suas vantagens no sentido de ampliar as desigualdades sociais e econômicas e de deteriorar uma sociedade justa, livre e equânime.

Apesar de demonstrar que a justiça como equidade é compatível com as exigências de eficiência econômica, Rawls afirma que os sistemas econômicos não podem estar desvinculados dos princípios de justiça e das questões morais. De fato, toda e qualquer 
desigualdade social e econômica somente pode ser aceita numa sociedade justa quando houver vantagens para todas as pessoas, independentemente da sua sorte natural ou social.

Mesmo sendo complexa, a teoria rawlsiana aponta clara e objetivamente os caminhos necessários para a construção de uma sociedade democrática e justa e para a diminuição das desigualdades sociais e econômicas.

\section{REFERÊNCIAS BIBLIOGRÁFICAS}

ALTMAN, Max. Hoje na História: Igreja acaba com Index de livros proibidos. Disponível em: <https://operamundi.uol.com.br/politica-e-economia/3594/hoje-na-historiaigreja-acaba-com-index-de-livros-proibidos>. Acesso em 12 de fevereiro de 2021.

BITTAR, Eduardo C. B.; ALMEIDA, Guilherme Assis. Curso de Filosofia do Direito. 10 ed., rev. e ampl. SP: Atlas. 2012.

GARGARELLA, Roberto. As teorias da justiça depois de Rawls: um breve manual de filosofia política. Tradução por Alonso Reis Freire e Revisão por Elza Maria Gasparotto e Eduardo Appio. SP: Martins Fontes. 2008.

KANT, Immanuel. Fundamentação da Metafísica dos Costumes. Tradução: Paulo Quintela. 2a ed. Lisboa: Edições 70. 2019.

São Paulo. 2010.

Metafísica dos costumes. Tradução por Edson Bini. $1^{\text {a }}$ ed. São Paulo: Folha de

LOVETT, Frank. Uma Teoria da Justiça, de John Rawls. Tradução: Vinicius Figueira. Porto Alegre: Penso. 2013.

RAWLS, Jonh. Uma Teoria da Justiça. $3^{\text {a }}$ ed. traduzido por Jussara Simões. SP: Martins Fontes. 2008.

Martins Fontes. 2011.

O Liberalismo Político. Ed. ampl. Traduzido por Alvaro de Vita. SP: WMF

ROUSSEAU, Jean-Jacques. Do Contrato Social. $1^{a}$ ed. SP: Folha de São Paulo. 2010.

SANDEL, Michael J. Justiça: o que é fazer a coisa certa. Tradução de Heloisa Matias e Maria Alice Máximo. 16 ed. RJ: Civilização Brasileira. 2014.

VITA, Álvaro de. O liberalismo igualitário: sociedade democrática e justiça internacional. SP: WMF Martins Fontes. 2008.

Apresentação da Edição Brasileira. In RAWLS, Jonh. Uma Teoria da Justiça.

$3^{\mathrm{a}}$ ed. traduzido por Jussara Simões. SP: Martins Fontes. 2008(a). 